\title{
Dry Powder Diffusion Mixing
}

National Cancer Institute

\section{Source}

National Cancer Institute. Dry Powder Diffusion Mixing. NCI Thesaurus. Code C113026.

Mixing of dry ing redients by repetitive tumbling. 